\title{
O currículo cultural da educação física e os significados das práticas corporais: análise de uma prática pedagógica
}

\section{The cultural curriculum of the phisical education and the meanings of bodily practices: analyze of a pedagogical practice}

\section{El currículo cultural de la educación física y los significados de las prácticas corporales: análisis de una práctica pedagógica}

\footnotetext{
iD Abília Ana de Castro Neta

Universidade Estadual do Sudoeste da Bahia, Vitória da Conquista, Bahia, Brasil E-mail: bia_gbi@hotmail.com

(9) Drieli Fernandes Boa Sorte Universidade do Estado da Bahia, Guanambi, Bahia, Brasil E-mail: drieligbi@hotmail.com

(iD) Glaurea Nádia Borges de Oliveira Universidade do Estado da Bahia, Guanambi, Bahia, Brasil E-mail: gnoliveira@uneb.br

iD Berta Leni Costa Cardoso Universidade do Estado da Bahia, Guanambi, Bahia, Brasil E-mail: bcardoso@uneb.br

iD(9) Marlon Messias Santana Cruz Universidade do Estado da Bahia, Guanambi, Bahia, Brasil. E-mail:mmscruz@uneb.br
}

Resumo: Esta investigação objetivou analisar as possíveis marcas do currículo cultural da Educação Física no modo como os alunos se relacionam com os significados das práticas corporais. Trata-se de uma 
pesquisa qualitativa, consubstanciada por uma intervenção pedagógica. Os sujeitos desta pesquisa foram os alunos do $4^{\circ}$ ano do Ensino Fundamental I, de uma escola pública do município de Guanambi-BA. É possível inferir que a problematização dos significados conferidos às práticas corporais tematizadas criou condições para hibridizar discursos e intercambiar conhecimentos. As significações inicialmente atribuídas às práticas investigadas foram sendo desestabilizadas, conquanto a legitimação dessa abertura dependa de circunstâncias que transcendem os limites da escola.

Palavras-chave: Educação Física escolar. Currículo cultural. Práticas corporais.

\begin{abstract}
This research aimed to analyze the possible traces of cultural curriculum of Physical Education in how students relate to the meanings of bodily practices. It is a qualitative research, concretized by a pedagogical intervention. The subject of this research was the 4th grade students of the elementary school, of a public school in the city of Guanambi-BA. It is possible to infer that the problematization of the meanings given to themed bodily practices created conditions to weld speeches and exchange knowledge. The meanings initially assigned to investigated practices were being destabilized, although the legitimacy of this gap depends on circumstances that transcend the boundaries of the school.
\end{abstract}

Keywords: School Physical Education. Cultural Curriculum. Bodily Practices

Resumen: Esta investigación objetivó analizar las posibles marcas del currículo cultural de la Educación Física en el modo como los alumnos se relacionan con los significados de las prácticas corporales. Se trata de una investigación cualitativa, consubstanciada por una intervención pedagógica. Los sujetos de esta investigación fueron los alumnos del $4^{\circ}$ Año de la Enseñanza Fundamental I. Es posible inferir que la problematización de los significados conferidos a las prácticas corporales tematizadas creó condiciones para hibridar discursos e intercambiar 
conocimientos. Las significaciones inicialmente atribuidas a las prácticas investigadas han sido desestabilizadas, si bien la legitimación de esa apertura depende de circunstancias que trascienden los límites de la escuela.

Palabras-clave: Educación Física escolar. Currículo cultural. Prácticas corporales.

Submetido em: 19/09/2018

Aceito em: 21/10/2019 


\section{Introdução}

A contemporaneidade é composta por diferentes culturas, configuradas por identidades múltiplas que se relacionam, confrontam-se, reformulam-se, afirmam-se e se hibridizam a todo instante (HALL, 1992). Essa condição produz novas responsabilidades à escola e ao currículo, colocando-os diante da demanda por reconhecimento e potencialização das vozes das culturas marginalizadas. Para Silva (2009), todos os currículos projetam determinadas identidades, negando outras formas de ser e agir e gerando desigualdades nas relações entre os sujeitos.

Com base nesses pressupostos há, no âmbito da Educação Física, um coletivo de professores - o Grupo de Pesquisas em Educação Física Escolar da Faculdade de Educação da Universidade de São Paulo (GPEF/FEUSP) - que, desde 2004, estuda, discute e experimenta uma perspectiva curricular que deseja fomentar a compreensão e o questionamento dos processos de fixação de sujeitos que atravessam as práticas corporais: um currículo das diferenças, denominado currículo cultural. Esse currículo, substancializado em diferentes escritos, a exemplo de Neira $(2011 ; 2015)$ e Neira e Nunes (2009; 2011), objetiva a formação de sujeitos dispostos a lutar por condições de vida e por relações sociais mais democráticas. Um currículo de Educação Física comprometido com essa visão busca confrontar a reprodução das significações culturais dominantes, presentes, por exemplo, nas propostas que deixam de interrogar as relações de poder que perpassam a produção das práticas corporais (NEIRA, 2014).

O currículo cultural começa a transpor os contornos do GPEF, alcançando outros territórios, como aquele em que reside a presente pesquisa. Impelido pelos pressupostos desse currículo, este estudo foi realizado por meio de uma intervenção pedagógica proposta pelo estágio curricular supervisionado do curso de Licenciatura em Educação Física do Campus XII da Universidade do Estado da Bahia (UNEB/Campus XII). Buscou-se, por conseguin- 
O currículo cultural da educação física e os significados das práticas corporais...

Abília Ana de Castro Neta • Drieli Fernandes Boa Sorte • Glaurea Nádia Borges de Oliveira • et. al...

te, responder à seguinte questão: quais as marcas de uma prática pedagógica orientada pelo currículo cultural da Educação Física no modo como os alunos se relacionam com os significados das práticas corporais?

Essa perspectiva curricular prestigia, desde seu planejamento, estratégias democráticas para a definição dos conteúdos e atividades de ensino; valoriza a reflexão crítica sobre práticas da cultura corporal que de algum modo estão presentes no universo vivencial dos alunos, para, em seguida, aprofundá-las e ampliá-las mediante o diálogo com outras vozes e outras manifestações corporais (NEIRA, 2010).

O currículo cultural da Educação Física fundamenta-se na teorização pós-crítica. Destaca-se, sobretudo, a influência dos estudos culturais e do multiculturalismo crítico, que passa a dividir espaço com outras análises abarcadas por essa teorização, como as provenientes do pós-estruturalismo e do pós-colonialismo. No que concerne aos estudos culturais, Neira e Nunes (2011, p. 672673) salientam que, a partir desse campo,

[...] o currículo da Educação Física também pode ser imaginado sob o modelo da textualidade. Enquanto texto, envolve práticas, estruturas institucionais e as complexas formas de atividade que estas requerem, condições legais e políticas de existência, determinados fluxos de poder e conhecimento, bem como uma organização semântica específica de múltiplos aspectos. Simultaneamente, esse texto só existe dentro de uma rede de relações intertextuais (a rede textual da cultura corporal, da cultura escolar, da prática pedagógica). Trata-se de uma entidade ontologicamente mista e para a qual não pode haver nenhuma forma "correta" ou privilegiada de leitura. Tal perspectiva questiona e ajuda a compreender o privilégio que determinados grupos possuem para fazer valer suas concepções de mundo, sociedade e práticas corporais, por exemplo. 
O currículo cultural da educação física e os significados das práticas corporais...

Abília Ana de Castro Neta • Drieli Fernandes Boa Sorte • Glaurea Nádia Borges de Oliveira • et. al...

Para os estudos culturais, a cultura é o terreno em que os significados cindem-se e podem ser contestados. Como território de luta pela significação, é na cultura que os grupos marginalizados tentam resistir às significações dos grupos dominantes, ao mesmo tempo em que a negociação de sentidos implicada nesse processo borra as fronteiras identitárias (HALL, 1997).

O multiculturalismo crítico, por seu turno, surge imbricado nas lutas sociais dos anos 1960/70 e aos poucos vai se constituindo como uma proposta no campo do currículo. Um currículo respaldado por essa concepção não se restringiria, pois, a ensinar a tolerância e o respeito, mas se sustentaria numa análise dos processos pelos quais as diferenças são produzidas através das relações de poder. Nesse horizonte teórico,

[...] a diferença, mais do que tolerada ou respeitada, é colocada permanentemente em questão. Embora o multiculturalismo crítico opere com base nas categorias centrais de classe, etnia e gênero, ele atua em prol de todos os grupos subordinados [...] (NEIRA, 2008, p. 4).

Com o esteio dessas análises, o currículo cultural da Educação Física forja os seguintes princípios: articulação com os objetivos educacionais orientadores das ações da escola, reconhecimento da cultura corporal da comunidade, rejeição ao daltonismo cultural, justiça curricular, descolonização do currículo e ancoragem social dos conhecimentos (NEIRA, 2011).

A Educação Física cultural se posiciona, assumidamente, a favor dos que ao longo do tempo não viram suas produções culturais contempladas pelos currículos escolares. Em vez de camuflar as diferenças para que não possam ser vistas, promove o confronto e abre espaço para que os alunos externem e analisem os sentimentos e impressões que eclodem nos momentos de divergência. Com suas intervenções, os professores ajudam os estudantes a identificarem vestígios de preconceitos conectados às práticas corporais, procurando desestabilizar as posições dos alunos por 
O currículo cultural da educação física e os significados das práticas corporais...

Abília Ana de Castro Neta • Drieli Fernandes Boa Sorte • Glaurea Nádia Borges de Oliveira • et. al...

meio da própria argumentação ou então recorrem a enfoques que explicitem as diferenças (NEIRA, 2011).

O ponto de partida para o trabalho pedagógico é a prática corporal contextualizada, ou seja, a ocorrência social das brincadeiras, danças, lutas, esportes e ginásticas. É o que permite aos docentes empreender, junto aos estudantes, uma séria e compromissada análise dos temas estudados. Com isso, o currículo amplia a possibilidade de compreensão do contexto social, histórico e político de produção e reprodução das manifestações corporais.

\section{Metodologia}

Esta pesquisa é de cunho qualitativo, que, conforme Goellner et al. (2010, p. 382) "transforma os colaboradores de um estudo em coautores e protagonistas dos processos metodológicos" permitindo flexibilidade na conduta do estudo, enfatizando os interesses da pesquisa no processo e não apenas no resultado.

O estudo foi realizado a partir de uma intervenção pedagógica, cujos procedimentos nortearam-se pelos princípios do currículo cultural da Educação Física. Neira (2011) nos apresenta possibilidades didáticas para a sua concretização, as quais foram consideradas na construção das atividades realizadas neste trabaIho: mapeamento, tematização, ressignificação, aprofundamento, ampliação, registros e avaliação. Assim, iniciamos pelo processo denominado mapeamento, que tem como intento

“[...] identificar quais manifestações corporais estão disponíveis aos alunos, bem como aquelas que, mesmo não compondo suas vivências, encontram-se no entorno da escola ou no universo cultural mais amplo. Mapear também significa levantar os conhecimentos que os alunos possuem sobre uma determinada prática corporal" (NEIRA, 2011, p. 107). 
O currículo cultural da educação física e os significados das práticas corporais...

Abília Ana de Castro Neta • Drieli Fernandes Boa Sorte • Glaurea Nádia Borges de Oliveira • et. al...

É por meio do mapeamento que se define a temática de estudo e que se mantêm uma atitude atenta às significações que circundam o trabalho pedagógico. Na prática pedagógica aqui descrita, o basquete foi escolhido para ser tematizado.

A tematização implica a elaboração de atividades de ensino que visam a possibilitar diferentes experiências com as manifestações corporais selecionadas a partir do mapeamento, fazendo emergir os significados que Ihes dão forma, confrontando-os, problematizando-os e ampliando-os. Isso permite ressignificá-las segundo as características dos alunos, aprofundar os conhecimentos inicialmente disponíveis e promover um diálogo com outras fontes (NEIRA, 2011).

Desse modo, os alunos são convidados a produzirem novas formas de vivenciar a prática em questão e a relacionarem esse processo com a própria prática investigada e o contexto social mais amplo, processo este denominado ressignificação.

Durante o aprofundamento e a ampliação, realizam-se atividades de estudo do contexto social, histórico e político de produção e reprodução da prática corporal em foco. Essa ancoragem pode ajudar a desconstruir as representações pejorativas eventualmente postas em circulação, como também a travar contato com outras formas de ver. O tratamento profundo do tema requer o engajamento do professor na proposta, a investigação do assunto e a seleção de materiais adequados. As atividades de aprofundamento analisam as razões que impulsionam as modificações de determinada prática corporal. Nessa operação, as questões de etnia, classe social, gênero, religião, deficiências, entre outras, são obrigatoriamente problematizadas. Enquanto isso, as atividades de ampliação permitem o conhecimento dos pontos de vista dos grupos e pessoas que criam e recriam a manifestação cultural. $\mathrm{Na}$ ausência dessas situações didáticas, os estudantes permanecem à mercê de perspectivas tendenciosas, que relacionam as brincadeiras, danças, lutas, esportes e ginásticas a finalidades mercadológicas de consumo, quase sempre embebidas de posições precon- 
O currículo cultural da educação física e os significados das práticas corporais...

Abília Ana de Castro Neta • Drieli Fernandes Boa Sorte • Glaurea Nádia Borges de Oliveira • et. al...

ceituosas referentes aos grupos que recusam a submissão (NEIRA; NUNES, 2009).

Por fim, outra ação pedagógica que o currículo cultural da Educação Física sugere são os registros e a avaliação. Neira (2011, p. 159) assevera que "[...] no decorrer das atividades de ensino, as anotações das observações e análises do cotidiano das aulas possibilitam a reunião de informações necessárias para avaliação do trabalho pedagógico".

Postas as possibilidades didático-metodológicas do currículo cultural, resta caracterizar o lócus desta investigação. A escola em que foi realizado o estudo funciona no período diurno e situa-se numa região periférica da cidade de Guanambi-BA. Os alunos, em sua maioria, são oriundos de famílias de baixo poder econômico, residentes do bairro onde se localiza a escola e de bairros vizinhos ${ }^{1}$. Os sujeitos deste estudo foram os alunos do $4^{\circ}$ Ano do Ensino Fundamental I, com faixa etária de 8 a 12 anos. As aulas ocorriam semanalmente, às sextas-feiras, das 13h10min às 15h30min, entre os meses de abril e junho de 2017.

As informações necessárias à elucidação do problema da pesquisa foram produzidas no contexto da intervenção pedagógica proposta pelo estágio curricular supervisionado e posteriormente sistematizadas e analisadas. Essas informações foram substancializadas por meio de registros reflexivos elaborados cotidianamente, os quais foram transcritos com detalhes e impressões relativos às aulas e aos seus acontecimentos. Esses registros consistem em uma das estratégias adotadas pelo estágio e neles foram narradas as atividades desenvolvidas, com comentários, reflexões e medidas utilizadas para superar os desafios e obstáculos encontrados.

Utilizamos também, como fonte para a obtenção dos dados, os materiais que os alunos produziram durante as aulas (textos, desenhos, registros diversos), assim como a gravação das discussões e rodas de conversa. Para isso, fizemos uso de um gravador, de modo que fosse ampliado o poder de registro das falas dos

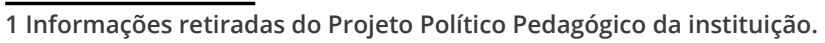


O currículo cultural da educação física e os significados das práticas corporais...

Abília Ana de Castro Neta • Drieli Fernandes Boa Sorte • Glaurea Nádia Borges de Oliveira • et. al...

alunos e a captação de elementos de comunicação que pudessem ser significativos, tais como pausas, dúvidas ou entonação da voz, aprimorando, assim, a compreensão da narrativa. Autores como Patton (1990) e Rojas (1999) corroboram este indicativo, pois o gravador preserva o conteúdo original e aumenta a acurácia dos dados coletados. Apresentaremos, a seguir, algumas falas dos alunos, que serão mencionados com nomes fictícios para preservamos a sua identidade. Para a análise dos dados, recorremos à descrição crítica.

\section{Resultados e discussão}

Sob a luz do referencial curricular que subjaz o estudo e a fim de analisar as possíveis marcas do currículo cultural da Educação Física no modo como os alunos se relacionam com os significados das práticas corporais, os dados obtidos foram discutidos a partir de duas categorias: "Os significados atribuídos às lutas" e "Os significados atribuídos ao basquete". No entanto, como este artigo trata-se de um recorte, apresentaremos somente alguns resultados da última categoria, referentes às situações vivenciadas na segunda etapa do estágio, em torno do tema basquete.

\section{Os significados atribuídos ao basquete}

O mapeamento inicial materializou-se a partir de uma brincadeira na qual os alunos ficaram dispostos em círculo, sentados em suas respectivas cadeiras, sendo que um deles se encontrava no centro. Essa criança deveria apontar uma característica - física ou acessórios utilizados - dos demais, de modo que os outros deveriam levantar de seus lugares e tentar, imediatamente, trocar de lugar. $\mathrm{O}$ aluno que se encontrava na parte central do círculo teria também que ocupar um determinado local. Desse modo, sempre 
O currículo cultural da educação física e os significados das práticas corporais...

Abília Ana de Castro Neta • Drieli Fernandes Boa Sorte • Glaurea Nádia Borges de Oliveira • et. al...

haveria um aluno ao centro para reiniciar a brincadeira. O aluno que se situava no centro responderia alguns dos nossos questionamentos: O que é esporte? Qual modalidade de esporte você conhece ou pratica? Em quais espaços? Quem são as pessoas que podem participar? Quais são as características e especificidades desse esporte? Direcionamos o mapeamento para o esporte porque, naquele período, esse conjunto de práticas corporais estava previsto no Projeto Político Pedagógico da escola e nas orientações da Secretaria Municipal de Educação.

Os esportes mencionados foram futebol, basquete, vôlei, atletismo, tênis, ciclismo, natação, dentre outros. Durante a dinâmica, também foi citada a capoeira. Notamos, ainda, que os alunos constantemente faziam referência ao boxe e judô, bem como às suas especificidades e implicações. Após a brincadeira, as crianças realizaram registros pictográficos, ampliando o leque de manifestações. A prática corporal selecionada para ser tematizada foi o basquete, em função de ter sido mencionada, notadamente, com maior regularidade pelos alunos. Na aula inicial, tivemos como finalidade mapear os conhecimentos dos alunos acerca desse esporte.

O basquete deve ser jogado com as mãos! (Paulo)

No basquete deve ficar quicando a bola! (Ronaldo)

Tem que bater a bola no chão e jogar para cima, para fazer ponto! (Gustavo)

As pessoas altas que jogam o basquete, porque as pessoas pequenas não alcançam. (Higor)

Ei tia, se segurar a bola é falta! (Laura)

O basquete é difícil para quem nunca fez tia! (Ana)

A cesta do basquete no baixo fica muito fácil, em cima fica difícil! (Luan)

O acessório do basquete é a cesta, a bola e outros instrumentos! (Pedro) 
O currículo cultural da educação física e os significados das práticas corporais...

Abília Ana de Castro Neta • Drieli Fernandes Boa Sorte • Glaurea Nádia Borges de Oliveira • et. al...

No decorrer do processo de tematização do basquete, realizamos discussões e vivências com o intuito de trocar experiências e ampliar os conhecimentos inicialmente acessados. Santos e Neira (2016) preconizam que um dos propósitos da tematização é identificar as conexões entre o objeto de estudo e os acontecimentos culturais e políticos. Partindo desse pressuposto, discutimos as configurações e especificidades que diferenciam o basquete de outras práticas, conversamos sobre sua gênese, seus praticantes, a que grupos sociais pertence, em quais espaços se realiza, quais acessórios utilizados, quando e onde participar, quais os procedimentos envolvidos (regras e fundamentos), refletimos sobre questões de ordem social, política, econômica, de gênero etc.

Iniciamos, assim, as vivências na quadra. Algumas regras já haviam surgido no debate em sala, então partimos delas para a organização da atividade. Ao discutirmos a divisão das equipes, inicialmente foram sistematizadas divisões por gênero e, posteriormente, equipes mistas. Essa estrutura surgiu a partir de uma questão organizacional. Não interferimos no jogo, apenas filmamos essa primeira vivência, com a intenção de ilustrar a roda de conversa que teríamos na aula seguinte, bem como pontuar alguns fatos ocorridos durante a partida. Na aula subsequente, ampliamos as discussões quanto às regras, apresentando aos alunos um vídeo de uma partida profissional de basquete para elencarmos, coletivamente, as regras oficiais do esporte, confrontando ambos os vídeos. Após discutirmos e adensarmos o debate, retornamos às vivências. Quando necessário, fazíamos ingerências de modo que pudéssemos, juntos, refletir e ressignificar o repertório gestual.

Para ampliar e aprofundar os conhecimentos a respeito da prática corporal em foco foram planejados momentos para assistir a documentários e vídeos sobre as especificidades do basquete, bem como a exibição de reportagens sobre jogadores e jogadoras, a realização de análise de discursos dos praticantes, entre outros. Atividades como essas demandam uma busca pessoal do professor para que oriente os alunos quanto aos materiais, formato, 
O currículo cultural da educação física e os significados das práticas corporais...

Abília Ana de Castro Neta • Drieli Fernandes Boa Sorte • Glaurea Nádia Borges de Oliveira • et. al...

procedimentos, pessoas envolvidas etc. Continuamos discutindo a gênese e as características do esporte, assim como as principais regras e fundamentos.

Jogam cinco jogadores de cada lado. (Marcos)

Ei tia, o reserva serve para substituir se alguém machucar ou tiver cansado! (Luan)

O basquete tem quatro tempos de 10 minutos, no total 40 minutos. (Gustavo)

Ah tia, no futebol é 45 minutos para cada, né? (Paulo)

No basquete a gente não marca gol, marca ponto. (Paulo)

Ei tia, a diferença do futebol para o basquete é que no futebol tem que ter o goleiro e no basquete não! (Paulo)

O lance livre é igual a falta no futebol. (Paulo)

O basquete passa menos na TV que o futebol. (Paulo)

Paulo iniciou uma série de comentários, relacionando o basquete ao futebol. Convicto de seu posicionamento, o aluno deixou muito clara sua preferência pelo futebol. Entretanto, a partir das nossas aulas, Paulo ampliou seu olhar sobre o basquete, demonstrando mais interesse por essa prática. Com base no discurso do aluno quanto à limitada apresentação do basquete na TV (comparado ao futebol), adensamos a discussão, refletindo sobre a relação entre mídia e esporte e os interesses que envolvem essa relação.

Apresentar aos alunos diferentes discursos, sob óticas distintas, e confrontar esses discursos, fazendo-os pensar e analisar, perceber as contradições, é um dos objetivos dessa estratégia. Aprofundar e ampliar o conhecimento pressupõe levar os alunos a outras dimensões e possibilidades. Levá-los a lugares com os quais eles nunca tiveram contato, lugares esses que destoam de cenários já vistos, e fazê-los perceber as diferenças culturais e suas representatividades; colocá-los diante de discursos diferentes sobre assuntos distintos, como o discurso da televisão, de um membro da comunidade, de um praticante de uma determinada moda- 
O currículo cultural da educação física e os significados das práticas corporais...

Abília Ana de Castro Neta • Drieli Fernandes Boa Sorte • Glaurea Nádia Borges de Oliveira • et. al...

lidade esportiva; tudo isso são atividades que visam a aprofundar e ampliar os conhecimentos quanto às práticas da cultura corporal (NEIRA, 2011). Em função desses recursos, os alunos começaram a entender as dimensões da prática corporal que estava sendo investigada com maior profundidade.

Em outro momento, ao discutirmos sobre as vitórias e derrotas decorrentes de uma partida, Luan iniciou uma série de comentários:

Ei tia, se o time perder ele vai lá e quebra os vidros das janelas do estádio! (Luan)

A partir da fala do aluno, questionamos se esse era o meIhor modo de reagir diante de uma derrota. Imediatamente, Luan afirmou:

É certo! Quando o time ganha fica provocando o que perdeu! (Luan)

Ei tia, o time do meu pai perdeu né, tava cheio de seguranças, aí meu pai espancou os caras, mais meu tio! [...]. (Luan)

Por conseguinte, propiciamos aos alunos a reflexão sobre a violência no âmbito do esporte. A violência nos estádios ou ginásios é um fenômeno imbricado na teia social em que é produzido, como observado na fala do aluno. Para adensarmos o debate, nos respaldamos nas reflexões de Pimenta $(2000$, p. 122)

\footnotetext{
A violência vem ganhando parte significativa na agenda social, em especial nos veículos de comunicação de massa, parecendo assumir o epicentro das preocupações do poder público e do homem contemporâneo. No entanto, merece ser observada por outros ângulos cada vez menos policialescos ou midiáticos, para evitar que seja utilizada, apenas, como cenário de 'espetáculo' e 'banalização'.
} 
O currículo cultural da educação física e os significados das práticas corporais...

Abília Ana de Castro Neta • Drieli Fernandes Boa Sorte • Glaurea Nádia Borges de Oliveira • et. al...

Para avaliar o trabalho realizado, repensar as ações e conhecer melhor as formas de expressão dos alunos, Neira e Nunes (2006) recomendam uma atenta elaboração de registros das atividades desenvolvidas, que poderão incluir os encaminhamentos efetuados pelo docente e as respostas dos estudantes, bem como o arquivamento dos materiais produzidos durante as aulas.

\begin{abstract}
A documentação facilita a análise do percurso de aprendizagem estabelecido pelo grupo. Uma vez que toda descoberta realizada acerca de variações nas práticas corporais pode ser novamente experimentada e transformada, é aconselhável registrar as experiências - por parte do docente e dos estudantes -, pois os materiais descobertos e analisados (fotos, reportagens, relatos, anotações, modificações nas músicas, regras, formas de brincar e realizar os movimentos, etc.) constituem importante documentação para a confecção dos portfólios do trabalho [...] (NEIRA; NUNES, 2009, p. 52).
\end{abstract}

Nessa perspectiva, fizemos uso dos registros reflexivos e em áudio, assim como dos materiais que os alunos produziram durante as aulas, como ferramenta para a avaliação do trabalho pedagógico. Numa roda de conversa, revisitamos o percurso triIhado. Durante esse momento, discutimos a respeito da presença das mulheres no basquete, analisando imagens da ex-jogadora Hortência Marcari e, posteriormente, ampliamos o debate, refletindo sobre a inserção feminina no esporte. Após uma série de problemáticas, refletimos quanto à disparidade entre os salários dos homens e das mulheres nos esportes. As meninas manifestaram insatisfação com essa disparidade:

Tia, ano passado a gente aprendeu que uma jogadora ganha bem menos. Eles pensam que as mulheres são mais fracas e isso não é verdade! Isso é uma injustiça! (Paula) 
O currículo cultural da educação física e os significados das práticas corporais...

Abília Ana de Castro Neta • Drieli Fernandes Boa Sorte • Glaurea Nádia Borges de Oliveira • et. al...

Essa desigualdade que assinala a participação feminina no esporte, rechaçada pela aluna, é também debatida por diversas pesquisas. Cardoso, Sampaio e Santos (2015), por exemplo, ao realizarem um estudo acerca das dimensões socioculturais do boxe, identificaram que o boxe feminino capitaliza poucos incentivos financeiros e pouca divulgação. Cardoso, Cárdenas e Sampaio (2013), por seu turno, investigaram os limites e preconceitos em modalidades esportivas hegemonicamente masculinas. À luz das teorias de gênero, foram analisadas a participação da mulher no esporte, bem como a discriminação sofrida pelas atletas e os desdobramentos disso. $O$ estudo identificou que as atletas sofrem ou sofreram algum tipo de preconceito em sua trajetória. Consoante a isso, Oliveira, Cherem e Tubino (2008) preconizam que, embora as crescentes transformações sociais estejam modificando antigas concepções no que se refere à questão de gênero, observa-se que persiste a existência de preconceitos e discriminações em relação à participação feminina em várias esferas da sociedade, incluindo o esporte.

Estendemos as discussões e realizamos as seguintes indagações: "Por que as mulheres recebem menos que os homens? Essa desigualdade encontra-se somente no âmbito do esporte? E no contexto social mais amplo, as mulheres são tratadas da mesma forma?" Diante das provocativas, um aluno posicionou-se da seguinte forma:

\section{Esporte não foi feito pra mulher! (João)}

A partir dessa fala, intensificamos os questionamentos com a finalidade de ampliar o debate e buscar possibilidades para desestabilizar e/ou desconstruir o estereótipo reproduzido pelo aluno. Nesse prisma, relata Neira (2011, p. 116): 
O currículo cultural da educação física e os significados das práticas corporais...

Abília Ana de Castro Neta • Drieli Fernandes Boa Sorte • Glaurea Nádia Borges de Oliveira • et. al...

[...] quando problematiza os temas da cultura corporal, o currículo se transforma em um espaço de crítica cultural, no qual se propicia o questionamento sobre tudo que possa ser "natural e inevitável". A ideia é colocar em xeque e permitir novos olhares sobre aquilo com que usualmente lidamos de modo acrítico.

Os questionamentos instigaram os estudantes a discutirem o assunto e explicitarem seus pontos de vista, ocasião em que afloraram representações a respeito da prática corporal, de sua gestualidade, de seus procedimentos, das suas formas de organização, das pessoas que dela participam, de como ela é apresentada e, portanto, construída. A problematização estimulou a turma a obter novos dados e travar contato com concepções diversas (NEIRA, 2016).

Com a prática pedagógica aqui apresentada, foi possível levar adiante um currículo composto por idas e vindas, aberto ao diálogo e a infinitas possibilidades. Em certo sentido, a tessitura das ações pedagógicas assemelha-se a um jogo de capoeira (NEIRA; NUNES, 2009). O capoeirista não joga com base em uma sequência preestabelecida e memorizada. Os golpes surgem como resposta à gestualidade do oponente, o que faz do bom capoeirista um leitor atento do texto produzido pelo seu adversário. Tal como o capoeirista se antecipa ao adversário e, prevendo seus golpes, o surpreende, o professor que coloca em ação o currículo cultural da Educação Física reorganiza as atividades de ensino a partir dos posicionamentos dos estudantes. Essa metáfora faz do planejamento um espaço vivo, participativo e imanente. Não há degraus que organizem os temas de ensino no currículo cultural. Realizado o mapeamento, o professor, assumindo a condição de artista, cria situações didáticas nas quais os estudantes possam vivenciar, ressignificar, aprofundar e ampliar seus conhecimentos (NEIRA, 2011).

Assim, a partir dos dados apresentados ao longo deste estudo e dos desdobramentos que deles surgiram, é possível inferir que a problematização dos significados conferidos às práticas corporais tematizadas criou condições para hibridizar discursos e intercam- 
O currículo cultural da educação física e os significados das práticas corporais...

Abília Ana de Castro Neta • Drieli Fernandes Boa Sorte • Glaurea Nádia Borges de Oliveira • et. al...

biar conhecimentos. Foi o desafio que lançamos aos educandos para que pudessem refletir sobre aspectos que não haviam sido percebidos de maneira crítica, apesar de constituírem as situações vividas.

\section{Considerações}

Comentários sobre uma prática corporal e posturas que colocam em evidência certas maneiras de significá-la demonstram que os discursos em circulação influenciam as posições dos sujeitos, os papéis que assumem, não somente nas aulas de Educação Física, mas no contexto social mais amplo (NEIRA, 2016). Essa é a condição com que nos defrontamos, cotidianamente, ao ensinarmos Educação Física na escola.

Mesmo tímida, nossa ação abriu espaços para que as significações inicialmente atribuídas ao basquete fossem desestabilizadas. Criou brechas, também, para discursos mais permeáveis aos princípios de uma sociedade multicultural e, quiçá, tenha ajudado a potencializar uma pedagogia da diferença. Por outro lado, é importante salientar que os campos teóricos que subsidiam o currículo cultural da Educação Física não têm a intenção de apresentar uma forma definitiva, única e pretensamente verdadeira para explicar a realidade, que é questionada e contestada, sem que, no entanto, se apontem soluções salvacionistas. O currículo, pensado a partir dessa teorização, não assume tarefas pautadas em ideias regulatórias; ao contrário, procura entender e problematizar a cultura, assim como as subjetivações que ela promove por meio do conhecimento e das práticas escolares (NEIRA, 2015).

Uma das contribuições dos estudos culturais para a pedagogia consiste no direcionamento dos olhares para as relações de poder que permeiam o currículo. Nesse sentido, ao dar a devida atenção a essas relações, torna-se necessário refletir acerca de suas origens e suas implicações, por meio de indagações e/ou provo- 
O currículo cultural da educação física e os significados das práticas corporais...

Abília Ana de Castro Neta • Drieli Fernandes Boa Sorte • Glaurea Nádia Borges de Oliveira • et. al...

cações que vislumbrem a mudança. Ao tematizarmos o basquete, emergiram questões que nos possibilitaram problematizar algumas das significações naturalizadas por meio das quais os alunos enxergavam essa manifestação. Foi possível apreender que o processo de desnaturalização apresentado nesse estudo, resultante das ações pedagógicas desenvolvidas, não é uma prática comum que se concretize nas aulas de Educação Física escolar, pois suscita o rompimento de paradigmas, construídos social, cultural e historicamente na área.

Quando se viram diante de outros significados acerca do basquete e das pessoas que dele participam, os estudantes perceberam algumas das múltiplas formas de afirmá-lo e vivenciá-lo. Mediante a problematização, eles foram incentivados a se dar conta de que suas verdades são produzidas culturalmente. Nesse conflito de proposições, construíram coletivamente novas maneiras de vivenciar o esporte, ressignificando suas experiências em meio ao dissenso de opiniões e sugestões. Ao ampliar seus saberes, os estudantes acessaram outros modos de fazer e pensar o mesmo tema.

Mesmo cientes dos limites da nossa ação pedagógica, nosso propósito foi confrontar os estudantes com algumas das estratégias empregadas para tornar hegemônicos determinados significados alusivos às práticas corporais, enquanto outros são negados, desprezados ou esquecidos. Quem sabe, com isso, eles possam vir a se perceber como sujeitos em meio ao jogo do poder cultural. Assim, não podemos fazer considerações finais, mas sim encarar o trabalho com o teor da continuidade, já que a cultura é algo que se transforma, muda e se ressignifica a todo instante. O que consideramos aqui, portanto, são as possibilidades de um currículo que permita evidenciar todas as vozes, um currículo que siga para além das barreiras verticais, do diretismo e que abrace a diferença. Por fim, espera-se que as discussões derivadas desse processo investigativo, além de estimular a realização de futuros estudos na mesma direção, contribuam tanto para a prática pedagógica dos professores em formação, quanto para os docentes que já se 
encontram em exercício, a fim de que a prática desses sujeitos se torne cada vez mais comprometida com rumos democráticos.

\section{Referências}

CARDOSO, B. L. C.; CÁRDENAS, C. J.; SAMPAIO, T. M. V. Limites e preconceitos em modalidades hegemonicamente masculinas: o caso do boxe feminino. XVIII CONBRACE e V CONICE, Brasil, mai. 2013. Disponível em: http://cbce.tempsite.ws/congressos/index. php/conbrace2013/5conice/paper/view/5351/2871. Acesso em: 16 jul. 2018.

CARDOSO, B. L. C.; SAMPAIO, T. M. V.; SANTOS, D. S. Dimensões socioculturais do boxe: percepção e trajetória de mulheres atletas. Movimento, Porto Alegre, v. 21, n. 1, p. 139-154, jan./mar. de 2015.

GOELLNER et al. S. V. Pesquisa qualitativa na educação física brasileira: marco teórico e modos de usar. Revista da Educação Física/UEM, Maringá, v. 21, n. 3, p. 381-410. 2010. Disponível em: http://periodicos.uem.br/ojs/index.php/RevEducFis/article/ view/8682/5829\%20\%3E. Acesso em: 27 ago. 2018.

HALL, S. A centralidade da cultura: notas sobre as revoluções culturais do nosso tempo. Educação\& Realidade, Porto Alegre, v. 22, n², p. 15-46, jul./dez. 1997.

HALL, S. A identidade cultural na pós-modernidade. Rio de Janeiro: DP\&A, 1992.

NEIRA, M. G. A didática da Educação Física na perspectiva cultural. In: NEIRA, M. G.; NUNES, M. L. F. Educação Física cultural: escritos sobre a prática. Curitiba: Editora CRV, 2016.

NEIRA, M. G. Análises das representações dos professores sobre o currículo cultural da Educação Física. Interface - Comunic., Saúde, Educ., Botucatu-SP, vol. 14, n. 35, p. 783-795, 2010.

NEIRA, M. G. Educação Física. São Paulo: Blucher, 2011. 
NEIRA, M. G. O currículo cultural da Educação Física: uma resposta aos dilemas da contemporaneidade. Revista Linhas. Florianópolis, v. 16, n. 31, p. 276 - 304, mai./ago. 2015. NEIRA, M. G. 0 currículo da Educação Física frente à diversidade cultural: Um estudo de caso. $31^{\text {a }}$ Reunião Anual da Associação Nacional de Pós-Graduação e Pesquisa em Educação (Anped), p. 1-18, 2008, [Caxambu, MG].

NEIRA, M. G. Práticas corporais: brincadeiras, danças, lutas, esportes e ginásticas. São Paulo: Melhoramentos, 2014.

NEIRA, M. G.; NUNES, M. L. F. Contribuições dos Estudos Culturais para o currículo da Educação Física. Revista Brasileira Ciências do Esporte, vol. 33, n. 3., Porto Alegre, Julho/Set. 2011.

NEIRA, M. G.; NUNES, M. L. F. Educação Física cultural: escritos sobre a prática. Curitiba: Editora CRV, 2016.

NEIRA, M. G.; NUNES, M. L. F. Educação Física, Currículo e Cultura. São Paulo: Phorte, 2009.

NEIRA, M. G.; NUNES, M. L. F. Pedagogia da Cultura Corporal: crítica e alternativas. São Paulo: Phorte, 2006.

OLIVEIRA, G.; CHEREM, E. H. L.; TUBINO, M. J. G. A inserção histórica da mulher no esporte. Revista Brasileira de Ciência e Movimento, Brasília, v.16, n. 2, p. 117-125, 2008.

PATTON, M. Q. Qualitative Evaluation and Research Methods. London: SAGE; 1990.

PIMENTA, C. A. M. Violência entre torcidas organizadas de futebol. São Paulo em Perspectiva, 14(2), 2000, p. 122-128, v. 14, n. 2.

ROJAS, J. E. A. O indivisível e o divisível na história oral. In: MARTINELLI, M. L. Pesquisa qualitativa: um instigante desafio. São Paulo: Veras, 1999. p. 87-94.

SANTOS, I. L.; NEIRA, M. G. A tematização no ensino da Educação Física. NEIRA, M. G. Educação Física cultural. São Paulo: Blucher, 2016. 
O currículo cultural da educação física e os significados das práticas corporais...

Abília Ana de Castro Neta • Drieli Fernandes Boa Sorte • Glaurea Nádia Borges de Oliveira • et. al...

SILVA, T. T. Currículo e Identidade Social: Territórios Contestados. In: SILVA, T. T. (org.). Alienígenas na Sala de Aula: uma introdução aos estudos culturais em educação. Petrópolis: Vozes, 2009.

\section{Notas}

\section{Aprovação de comitê de ética em pesquisa}

Pesquisa aprovada pelo Comitê de Ética da Universidade do Estado da Bahia. Título: O currículo cultural da Educação Física e os significados das práticas corporais: análise de uma prática pedagógica. PUBLISHER

\section{Publisher}

Universidade Federal de Goiás. Faculdade de Educação Física e Dança. Publicação no Portal de Periódicos UFG. As ideias expressadas neste artigo são de responsabilidade de seus autores, não representando, necessariamente, a opinião dos editores ou da universidade. 